\title{
Epilepsy in a population of 6000 re-examined: secular trends in first attendance rates, prevalence, and prognosis
}

\author{
O C Cockerell, I Eckle, D M G Goodridge, J W A Sander, S D Shorvon
}

\begin{abstract}
It is important to document changes in the vital statistics of epilepsy in the general population so that the success or failure of prevention and treatment can be assessed and health provisions planned. A population of 6000 persons was studied 10 years apart to determine secular trends in the prevalence and prognosis of epilepsy. The lifetime prevalence of all patients with one or more afebrile seizures was $20 \cdot 3 / 1000(95 \% \mathrm{CI}$ $16 \cdot 9-24 \cdot 3)$ in 1983 and $21 \cdot 0 / 1000(95 \%$ CI $17 \cdot 6-25 \cdot 1)$ in 1993 . The prevalence of active epilepsy was $5 \cdot 3 / 1000(95 \%$ CI $3 \cdot 6-7 \cdot 5)$ in 1983 and $4 \cdot 3(95 \%$ CI $2 \cdot 8-6 \cdot 3)$ in 1993. To assess trends in incidence rates the annual first attendance rates were measured from 1964 to 1993 . Annual first attendance rates in children (age < 20 years) have declined from $152 \cdot 4 / 100$ $000(90 \%$ CI $106 \cdot 0-212 \cdot 9)$ in the years $1974-83$, to $60 \cdot 9 / 100000(90 \%$ CI $33 \cdot 0-$ $103 \cdot 3$ ) in the years from 1984-93, suggesting that the incidence of epilepsy in children is falling. Also noteworthy was the first attendance rates for epilepsy in elderly people (61-80 years) in the years $1984-93$, of $82 \cdot 0(90 \%$ CI $38 \cdot 5-154 \cdot 0)$, higher than in any other age group. This increase in the number of elderly patients with epilepsy is important, and has health planning implications, especially with the overall increase in the total elderly population. There was, however, no evidence that prognosis has significantly altered in the past 40 years.
\end{abstract}

\section{$(\mathcal{F}$ Neurol Neurosurg Psychiatry 1995;58:570-576)}

Keywords: epilepsy; secular trends; prevalence; prognosis

A number of factors may have influenced the epidemiology of epilepsy over the past century. Firstly, there have been major demographic alterations in the population structure. In the developed countries there has been a declining birth rate and a rising life expectancy with an increase in the number of elderly people. Epilepsy is more common in the early and later decades of life and, therefore, changes to the population structure should also change the age specific prevalence rates. Secondly, there may have been changes in proportion of different aetiologies that cause epilepsy. For instance, there has been a fall in perinatal mortality in the developed world, ${ }^{1}$ with a general improvement in perinatal health, so epilepsy that arises as a consequence of perinatal infection and trauma might also be expected to decline. This has led to suggestions that the incidence of epilepsy has fallen in the past decades in both Europe, and the United States. ${ }^{2-4}$ Lastly, the treatment of epilepsy have improved over the past three decades. We have seen the introduction of new antiepileptic drugs, better use of existing ones, and advances in the early recognition and treatment of status epilepticus, and other complications of epilepsy, and there has been speculation that there has been an improvement in the prognosis of epilepsy in recent years. ${ }^{56}$

In this study to determine trends in the dynamics of epilepsy epidemiology a population of 6000 persons was examined 10 years apart. The same general practice population was the subject of a study in $1983 .^{?}$

Subjects and methods

All patients with epilepsy in a population of 6000 (defined, as in 1983, as all the patients on the list of one general practitioner, DMGG, and the subsequent alphabetical names in the remainder of the practice list to bring the population to exactly 6000 ) were ascertained. Patients were identified by the same method of case ascertainment as was employed in 1983: all the general practitioner notes in the specified population of 6000 were examined, looking for a mention of epileptic seizures in letters, tests, and prescriptions, or in the actual general practitioner's hand written notes. We also supplemented this by looking for patients on the practice computer patient management system registered as having epileptic seizures, and for patients with a current antiepileptic drug prescription.

The same definition of a case as in 1983 was used-namely, a history of at least one non-febrile convulsion. ${ }^{7}$ All patients with definite seizures were included, as well as acute symptomatic seizures (seizures secondary to an acute cerebral insult, such as alcohol). All patients' notes were reviewed. Seizures were classified according to the 1981 International League Against Epilepsy (ILAE) revised classification of epileptic seizures. ${ }^{8}$ When classification was not possible on the information available, instead of assigning patients to a category of probable generalised tonic clonic seizures as had been done previously, ${ }^{7}$ they 
were now categorised as unclassifiable. Aetiology was based on ILAE guidelines (except that brain tumours were considered to be a remote symptomatic cause in the absence of progressive neurological decline). ${ }^{9}$ Active epilepsy, as for the previous study, was defined as any patient experiencing one or more seizures in the two years before the survey date. Other data collected were age, sex, and initial treatment (antiepileptic drugs started within the first six months), current treatment and the time of first and last seizure, and details of remission. Remission was defined as freedom from seizures, which could occur at any time, for two and four years. All the patients ascertained were then sent a questionnaire asking about current and past seizure activity, as well as the treatment of their epilepsy. The results of the postal survey were compared with the notes and any discrepancies discussed with the patient's general practitioner.

The demographic data of the 1983 practice population were obtained and compared with the 1993 population and this enabled estimations of the prevalence rates for the 1983 and 1993 practice populations. The age adjusted practice population was calculated from data obtained from the Office of Population Census and Surveys on the population of Tonbridge for the census years 1951, 1961, 1971,1981 , and 1991, and this was used to estimate annual age specific first attendance rates (see $\mathrm{Zielinski}^{10}$ ) for the periods $1948-63$, 1964-73, 1974-83, and 1984-93. First attendance rates were calculated for the survey populations of 1983 and 1993. The first attendance was the time of the first medical consultation which led to a diagnosis of epilepsy being made. First attendance rates were calculated per 100000 persons and given as an annual rate. Confidence limits to 95\% (95\% CI), and $90 \%$ for first attendance rates, were calculated. ${ }^{11}$

Prognosis was analysed with life table methods with an SPSS/PC statistical program.

\section{Results}

\section{DEMOGRAPHIC FEATURES}

Table 1 shows the age structure of the population surveyed and of patients with epilepsy in the two survey years. The social class breakdown for the town of Tonbridge (United Kingdom figures in parentheses) was: class I $9 \%(7 \%)$, class II $45 \%(30 \%)$, class III $24 \%$ (40\%), class IV $11 \%(14 \%)$, class V $6 \%(5 \%)$, and others $6 \%(4 \%) ; 93 \%$ of the population was born in England, 3.1\% in other parts of the British Isles.

In 1983122 patients with definite epilepsy were identified, and in 1993 we identified 126. Sixty four patients currently in the practice in 1993 had been identified in the 1983 survey and 62 were patients new to the practice or patients who had developed seizures since. Fifty eight patients from the original 6000 in 1983 had moved away or died. All 126 patients were identified from the records review and no extra cases were ascertained by the other methods alone.

The prevalence of all patients with one or more afebrile seizures was $20 \cdot 3 / 1000(95 \%$ CI $16 \cdot 9-24 \cdot 3)$ in 1983 and $21 \cdot 0 / 1000(95 \%$ CI $17 \cdot 6-25 \cdot 1)$ in 1993 , or $16 \cdot 7 / 1000(95 \%$ CI 13.5-20.4) for patients with two or more attacks in 1983, and $17 \cdot 0 / 1000(95 \%$ CI 13.9-20.7) in 1993. The prevalence for those with active epilepsy was $5 \cdot 3 / 1000(95 \%$ CI $3 \cdot 6-7 \cdot 5)$ in 1983 and $4 \cdot 3 / 1000(95 \%$ CI $2 \cdot 8-6 \cdot 3$ ) in 1993. The prevalence of unprovoked seizures (non-acute symptomatic) was $17 \cdot 2 / 1000(95 \%$ CI $14 \cdot 1-20 \cdot 9)$ in 1983 compared with $17 \cdot 7 / 1000(95 \%$ CI $14 \cdot 6-21 \cdot 5)$ in 1993.

\section{AGE AND SEX DISTRIBUTION}

Table 2 shows the age and sex specific rates. The overall prevalence rate of persons with a history of one or more afebrile seizures for men was $13 \cdot 7 / 1000(95 \%$ CI 9.8-18.6) and for women $27 \cdot 0 / 1000(95 \%$ CI $21 \cdot 4-33 \cdot 5)$ in 1983 , and $15 \cdot 4 / 1000(95 \%$ CI $11 \cdot 3-20 \cdot 5)$ for men and $26 \cdot 5 / 1000$ (95\% CI 21.0-32.9) for women in 1993. For patients with active epilepsy in the 1993 survey $(n=26)$ the age specific rates were: $4 \cdot 8 / 1000$ for ages $0-20$ years, $2 \cdot 7 / 1000$ for ages $21-60$ years, and $6 \cdot 1 / 1000$ for ages over 60 years.

\section{AETIOLOGY AND SEIZURE TYPE}

Tables 3 and 4 show the aetiology and seizure type. Thirty five per cent of patients had partial seizures in 1983 compared with $39 \%$ in 1993; $48 \%$ had generalised onset seizures in 1983 compared with $51 \%$ in $1993 ; 17 \%$ were unclassified in 1983 and $14 \%$ in $1993 ; 74 \%$ had epilepsy of unknown origin in 1983 and $76 \%$ in 1993.

FIRST ATTENDANCE RATE TRENDS

The overall average mean first attendance rate for the whole period 1948-83 calculated from the 1983 survey was $56 \cdot 5 / 100000 \quad(95 \%$ CI $47 \cdot 1-67 \cdot 7)$, and $45 \cdot 7 / 100000(95 \% \mathrm{CI}$ $38 \cdot 2-54 \cdot 6$ ) from 1948 to 1993 . The overall

Table 1 Age and sex of the 6000 population in 1983 and in 1993

\begin{tabular}{lrcrr}
\hline Age & Person & Male & Female & $\%$ \\
\hline & & 1983 & & \\
$0-10$ & 744 & 393 & 351 & $12 \cdot 4$ \\
$11-20$ & 868 & 456 & 412 & $14 \cdot 5$ \\
$21-30$ & 988 & 484 & 504 & $16 \cdot 4$ \\
$31-40$ & 1077 & 516 & 561 & $17 \cdot 9$ \\
$41-50$ & 742 & 402 & 340 & $12 \cdot 4$ \\
$51-60$ & 593 & 319 & 274 & $9 \cdot 9$ \\
$61-70$ & 456 & 221 & 235 & $7 \cdot 6$ \\
$71-80$ & 343 & 149 & 194 & $5 \cdot 7$ \\
$81+$ & 189 & 60 & 129 & $3 \cdot 2$ \\
Total & 6000 & 3000 & 3000 & 100 \\
& & & & \\
$0-10$ & 787 & 4993 & 381 & $13 \cdot 1$ \\
$11-20$ & 885 & 465 & 420 & $14 \cdot 8$ \\
$21-30$ & 841 & 439 & 402 & $14 \cdot 0$ \\
$31-40$ & 856 & 438 & 418 & $14 \cdot 3$ \\
$41-50$ & 865 & 444 & 421 & $14 \cdot 4$ \\
$51-60$ & 627 & 320 & 307 & $10 \cdot 5$ \\
$61-70$ & 512 & 241 & 271 & $8 \cdot 5$ \\
$71-80$ & 398 & 165 & 233 & $6 \cdot 6$ \\
$81+$ & 229 & 82 & 147 & $3 \cdot 8$ \\
Total & 6000 & 2986 & 3014 & 100 \\
\hline
\end{tabular}


Table 2 Demographics of patients with epilepsy in 1983 and 1993

\begin{tabular}{|c|c|c|c|c|c|c|c|c|c|c|}
\hline & \multicolumn{5}{|l|}{1983} & \multicolumn{5}{|l|}{1993} \\
\hline & Male & Female & Total & $\%$ & $95 \% C I$ & Male & Female & Total & $\%$ & $95 \% C I$ \\
\hline \multicolumn{11}{|c|}{ Age and sex distribution on onset of seizures in populations of 1983 and 1993} \\
\hline $\begin{array}{r}0-10 \\
11-20 \\
21-30 \\
31-40 \\
41-50 \\
51-60 \\
61-70 \\
71-80 \\
81+ \\
\text { Total }\end{array}$ & $\begin{array}{r}14 \\
8 \\
7 \\
2 \\
4 \\
1 \\
5 \\
0 \\
0 \\
41\end{array}$ & $\begin{array}{r}24 \\
22 \\
16 \\
2 \\
5 \\
4 \\
5 \\
3 \\
0 \\
81\end{array}$ & $\begin{array}{r}38 \\
30 \\
23 \\
4 \\
9 \\
5 \\
10 \\
3 \\
0 \\
122\end{array}$ & $\begin{array}{r}31 \\
25 \\
19 \\
3 \\
7 \\
4 \\
8 \\
3 \\
0 \\
100\end{array}$ & $\begin{array}{l}- \\
= \\
- \\
= \\
= \\
-\end{array}$ & $\begin{array}{r}20 \\
8 \\
7 \\
4 \\
3 \\
3 \\
1 \\
0 \\
0 \\
46\end{array}$ & $\begin{array}{r}28 \\
20 \\
12 \\
4 \\
6 \\
4 \\
1 \\
5 \\
0 \\
80\end{array}$ & $\begin{array}{r}48 \\
28 \\
19 \\
8 \\
9 \\
7 \\
2 \\
5 \\
0 \\
126\end{array}$ & $\begin{array}{r}38 \\
22 \\
15 \\
6 \\
7 \\
6 \\
2 \\
4 \\
0 \\
100\end{array}$ & $\begin{array}{l}- \\
- \\
- \\
- \\
- \\
-\end{array}$ \\
\hline \multicolumn{11}{|c|}{ Age and sex distribution at time of survey in populations of 1983 and 1993} \\
\hline $\begin{array}{r}0-10 \\
11-20 \\
21-30 \\
31-40 \\
41-50 \\
51-60 \\
61-70 \\
71-80 \\
81+ \\
\text { Total }\end{array}$ & $\begin{array}{r}3 \\
7 \\
9 \\
7 \\
4 \\
4 \\
5 \\
2 \\
0 \\
41\end{array}$ & $\begin{array}{r}3 \\
11 \\
12 \\
17 \\
13 \\
5 \\
9 \\
8 \\
3 \\
81\end{array}$ & $\begin{array}{r}6 \\
18 \\
21 \\
24 \\
17 \\
9 \\
14 \\
10 \\
3 \\
122\end{array}$ & $\begin{array}{r}5 \\
15 \\
17 \\
20 \\
14 \\
7 \\
11 \\
8 \\
3 \\
100\end{array}$ & $\begin{array}{l}z \\
= \\
= \\
= \\
= \\
-\end{array}$ & $\begin{array}{r}3 \\
5 \\
8 \\
11 \\
6 \\
7 \\
4 \\
2 \\
0 \\
46\end{array}$ & $\begin{array}{r}1 \\
8 \\
10 \\
19 \\
13 \\
13 \\
6 \\
9 \\
1 \\
80\end{array}$ & $\begin{array}{r}4 \\
13 \\
18 \\
30 \\
19 \\
20 \\
10 \\
11 \\
1 \\
126\end{array}$ & $\begin{array}{r}3 \\
10 \\
14 \\
24 \\
15 \\
16 \\
8 \\
9 \\
1 \\
100\end{array}$ & $\begin{array}{l}- \\
= \\
z \\
z \\
z \\
-\end{array}$ \\
\hline \multicolumn{11}{|c|}{ Age and sex specific prevalence rates per 100 persons for 1983 and 1993} \\
\hline $\begin{array}{r}0-10 \\
11-20 \\
21-30 \\
31-40 \\
41-50 \\
51-60 \\
61-70 \\
71-80 \\
81+ \\
\text { Total }\end{array}$ & $\begin{array}{r}7.6 \\
15.4 \\
18.6 \\
13.6 \\
10.0 \\
12.5 \\
22.6 \\
13.4 \\
\overline{13.7}\end{array}$ & $\begin{array}{r}8 \cdot 5 \\
26 \cdot 7 \\
23 \cdot 8 \\
30 \cdot 3 \\
38 \cdot 2 \\
18 \cdot 2 \\
38 \cdot 3 \\
41 \cdot 2 \\
23 \cdot 3 \\
27 \cdot 0\end{array}$ & $\begin{array}{r}8 \cdot 1 \\
20 \cdot 7 \\
21 \cdot 3 \\
22 \cdot 3 \\
22 \cdot 9 \\
15 \cdot 2 \\
30 \cdot 7 \\
29 \cdot 2 \\
15 \cdot 9 \\
20 \cdot 3\end{array}$ & $\begin{array}{l}- \\
- \\
- \\
- \\
- \\
-\end{array}$ & $\begin{array}{r}3 \cdot 0-17 \cdot 7 \\
12 \cdot 3-32 \cdot 7 \\
13 \cdot 2-32 \cdot 6 \\
14 \cdot 3-33 \cdot 2 \\
13 \cdot 3-36 \cdot 6 \\
7 \cdot 0-28 \cdot 9 \\
16 \cdot 8-51 \cdot 6 \\
14 \cdot 0-53 \cdot 7 \\
3 \cdot 3-46 \cdot 4 \\
16 \cdot 9-24 \cdot 3\end{array}$ & $\begin{array}{r}7 \cdot 4 \\
10 \cdot 8 \\
18 \cdot 2 \\
25 \cdot 1 \\
13 \cdot 5 \\
21 \cdot 9 \\
16 \cdot 6 \\
12 \cdot 1 \\
\overline{15} \cdot 4\end{array}$ & $\begin{array}{r}2.6 \\
19.0 \\
24 \cdot 9 \\
45 \cdot 5 \\
30 \cdot 9 \\
42 \cdot 3 \\
22 \cdot 1 \\
38.6 \\
6.8 \\
26.5\end{array}$ & $\begin{array}{r}5 \cdot 1 \\
14 \cdot 7 \\
21 \cdot 4 \\
35 \cdot 0 \\
22 \cdot 0 \\
31 \cdot 9 \\
19 \cdot 5 \\
27 \cdot 6 \\
4 \cdot 4 \\
21 \cdot 0\end{array}$ & $\begin{array}{l}- \\
z \\
z \\
z \\
z \\
-\end{array}$ & $\begin{array}{r}1 \cdot 4-13 \cdot 1 \\
7 \cdot 8-25 \cdot 1 \\
12 \cdot 7-33 \cdot 8 \\
23 \cdot 6-50 \cdot 1 \\
13 \cdot 2-34 \cdot 3 \\
19 \cdot 5-49 \cdot 1 \\
9 \cdot 4-35 \cdot 9 \\
13 \cdot 8-49 \cdot 4 \\
0 \cdot 1-24 \cdot 5 \\
17 \cdot 6-25 \cdot 1\end{array}$ \\
\hline
\end{tabular}

Table 3 Seizure classification of epilepsy in populations of 1983 and 1993

\begin{tabular}{lcc}
\hline & 1983 & 1993 \\
Seizure type & No (\%) & No (\%) \\
\hline Partial: & $1(1)$ & \\
Simple & $10(8)$ & $1(1)$ \\
Complex & $18(15)$ & $11(12)$ \\
Secondary generalised (SG) & $11(9)$ \\
Partial and SG & $14(11)$ & $22(17)$ \\
Generalised: & $50(41)$ & $46(37)$ \\
$\quad$ Tonic clonic & $4(3)$ & $9(7)$ \\
Absence & $5(4)$ & $9(7)$ \\
More than one type & $20(17)$ & $17(14)$ \\
Unclassifiable & $122(100)$ & $126(100)$ \\
Total & & \\
\hline
\end{tabular}

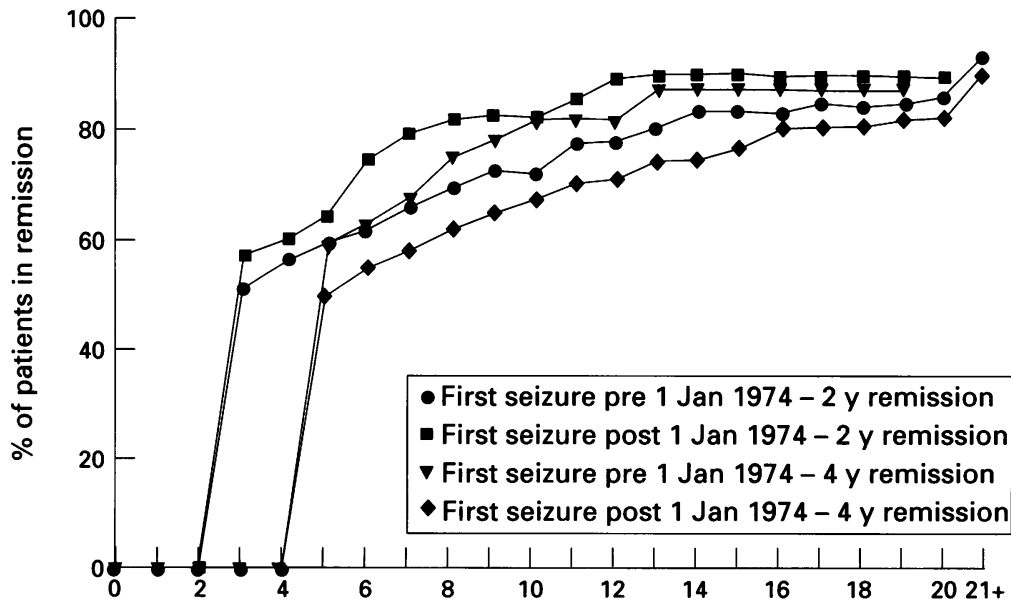

Time since onset of seizures (years)

Remission in all patients ( $n=184)$, comparing those diagnosed before and after 1 Fanuary 1974.
Table 4 Aetiology of epilepsy in populations of 1983 and 1993

\begin{tabular}{lcc}
\hline Aetiology & 1983 & 1993 \\
& No $(\%)$ & No $(\%)$ \\
\hline Unknown & $90(74)$ & $96(76)$ \\
Acute symptomatic: & $7(6)$ & $3(2)$ \\
$\quad$ Trauma & $3(2)$ & $1(1)$ \\
Vascular & $0(0)$ & $2(2)$ \\
Metabolic & $1(1)$ & $4(3)$ \\
Infection & $4(3)$ & $3(2)$ \\
Alcohol & $4(3)$ & $7(6)$ \\
Othert & $1(1)$ & $2(2)$ \\
Remote symptomatic: & $9(7)$ & $5(4)$ \\
Tumours & $2(2)$ & $1(1)$ \\
Vascular & $1(1)$ & $2(2)$ \\
Trauma & $122(100)$ & $126(100)$ \\
Other & & \\
Total & & \\
\hline
\end{tabular}

^Eclampsia, drugs, hypoxia.

†Associated with progressive neurological degenerative disease or severe neurological deficit present at birth.

annual sex specific rates were $33 \cdot 3 / 100000$ (95\% CI 24.4-44.3) for men and 58.0/100 000 (95\% CI 46.0-71.9) for women for 1948-93 calculated from the 1993 survey. Tables 5 and 6 show the age specific rates for persons under 20 years of age and the age specific first attendance rates for the years 1984-93. Annual first attendance rates in children (age $<20$ years) were $152 \cdot 4 / 100000 \quad(90 \% \quad \mathrm{CI}$ $106 \cdot 0-212.9)$ in the years $1974-83$ and $60 \cdot 9 / 100000(90 \%$ CI $33 \cdot 0-103 \cdot 3)$ in the years from $1984-93\left(\chi^{2}, \mathrm{P}<0.001\right)$.

PROGNOSIS

Over $65 \%$ of patients responded to the questionnaire and this enabled clarification of the seizure onset and remission dates in $20 \%$ of patients where this was not clear from the notes. Three patients denied all knowledge of their epilepsy despite convincing 
Table 5 First attendance rates: Secular trends in first attendance rates in children. Number of new cases between 1964 and 1993 and annual first attendance rate per 100000 in children

\begin{tabular}{|c|c|c|c|c|c|c|c|c|c|c|c|c|}
\hline \multirow[b]{2}{*}{ Age } & \multicolumn{4}{|c|}{$1964-73$} & \multicolumn{4}{|c|}{$1974-83$} & \multicolumn{4}{|c|}{$1984-93$} \\
\hline & No & Rate & $90 \% C I$ & $95 \% C I$ & No & Rate & $90 \% C I$ & $95 \% C I$ & No & Rate & $90 \% C I$ & $95 \% C I$ \\
\hline $\begin{array}{l}0-20 \\
\text { All ages }\end{array}$ & $\begin{array}{l}26 \\
45\end{array}$ & $\begin{array}{r}131 \cdot 7 \\
75 \cdot 0\end{array}$ & $\begin{array}{l}92 \cdot 3-182 \cdot 8 \\
57 \cdot 6-96 \cdot 2\end{array}$ & $\begin{array}{l}86 \cdot 0-193 \cdot 6 \\
54 \cdot 7-100 \cdot 5\end{array}$ & $\begin{array}{l}25 \\
31\end{array}$ & $\begin{array}{r}152 \cdot 4 \\
51 \cdot 7\end{array}$ & $\begin{array}{c}106 \cdot 0-212 \cdot 9 \\
37 \cdot 4-69 \cdot 7\end{array}$ & $\begin{array}{l}98 \cdot 6-225 \cdot 6 \\
35 \cdot 1-73 \cdot 4\end{array}$ & $\begin{array}{l}10 \\
29\end{array}$ & $\begin{array}{l}60 \cdot 9 \\
48 \cdot 3\end{array}$ & $\begin{array}{l}33 \cdot 0-103 \cdot 3 \\
34 \cdot 6-65 \cdot 9\end{array}$ & $\begin{array}{l}29 \cdot 2-112 \cdot 1 \\
32 \cdot 4-69 \cdot 6\end{array}$ \\
\hline
\end{tabular}

Table 6 Age specific first attendance rates in past decade. Number of new cases and annual first attendance rates per 100000 between 1984-93

\begin{tabular}{lrccc}
\hline Age & No & Rate & $90 \%$ CI & $95 \%$ CI \\
\hline $0-20$ & 10 & $60 \cdot 9$ & $33 \cdot 0-103 \cdot 3$ & $29 \cdot 2-112 \cdot 1$ \\
$21-40$ & 7 & $37 \cdot 2$ & $17 \cdot 5-69 \cdot 9$ & $14 \cdot 9-76 \cdot 6$ \\
$41-60$ & 4 & $28 \cdot 3$ & $9 \cdot 7-64 \cdot 7$ & $7 \cdot 7-72 \cdot 4$ \\
$61-80$ & 7 & $82 \cdot 0$ & $38 \cdot 5-154 \cdot 0$ & $32 \cdot 9-168 \cdot 9$ \\
$81+$ & 1 & $47 \cdot 8$ & $2 \cdot 4-227 \cdot 0$ & $1 \cdot 2-266 \cdot 2$ \\
Total & 29 & $48 \cdot 3$ & $34 \cdot 6-65 \cdot 9$ & $32 \cdot 4-69 \cdot 6$ \\
\hline
\end{tabular}

documentation to the contrary. The figure shows the two and four year remission curves for all patients from the 1983 and 1993 surveys with onset of epilepsy before and after 1 January 1974 (pre-1974, $\mathrm{n}=100$ and post$1974, \mathrm{n}=84$ ). The number of patients with active epilepsy was 32 in 1983, and 26 in 1993. For all patients, $61 \%$ achieved two year remission at four years, $81 \%$ at 10 years, and $74 \%$ achieved four year remission by 10 years. There were no significant differences between these analyses when performed from the 1983 compared with the 1993 surveys, or when performed for idiopathic or symptomatic epilepsy, or by age, sex, or seizure type.

\section{TREATMENT}

In 198347 patients (38.5\%) were receiving antiepileptic drugs compared with $47(37 \cdot 3 \%)$ in 1993 . Ninety six patients $(78 \cdot 7 \%)$ from the 1983 survey had received antiepileptic drugs at some time compared with $93(73.8 \%)$ in 1993.

\section{Discussion}

The general practitioner system in the United Kingdom offers considerable scope for studying the epidemiology of epilepsy. ${ }^{12}$ There is high coverage of the population with over 98\% registered with a general practitioner. The general practitioner initiates and documents all hospital contacts, including those that occurred without his or her initial knowledge. The general practitioner is responsible for all long term prescribing, as well as keeping the medical notes, which may go back to 1948, containing a patient's lifetime medical history with information on investigations and hospital care. The complete medical notes are transferred with the patient should they move. In the United Kingdom, the Office of Population Census and Survey keeps detailed data on population demographics and social structure down to the town level, and records go back to the beginning of the century.

In this study we used a combination of medical record review, information from the
1983 study, and a questionnaire to obtain data on each patient. In 1993 over $96 \%$ of patients had been referred to a neurologist or other physician and the notes gave a clear account of the seizures in letters, hospital summaries, or the original notes written by the general practitioner. Most (over 75\%) patients had had EEGs, and in recent years, CT or MRI $(52 \%$ of new onset cases in the past 10 years having CT). Because of the absence of a patient interview the determination of the exact number of seizures may have been inaccurate in some patients. The exact numbers of seizures, or patient attitudes to their treatment, were not being examined in this study, and we think that the lack of an interview does not detract from the validity of the data.

POPULATION OF TONBRIDGE

The population of the town of Tonbridge is homogenous compared with the rest of the United Kingdom. There are higher proportions in the higher social classes and the bulk of the population was born in the United Kingdom. Over the past 50 years the population has undergone some alteration. After the second world war the proportion of men between 20-40 years of age was significantly less than women and the proportions under 10 years of age was $15.6 \%$. This changed in the 1960 s, with an increase in the young male population together with a rising birth rate (over $18 \%$ in the under 10 age group). This then gradually fell to a level of $13 \%$ in the past two decades. Against this there has been a marginal increase in the number of elderly people, with $8.7 \%$ over 71 in 1951 , and $8.8 \%$ in 1992; the percentage over 81 has risen, especially in women. The population of the practice 6000 in 1983 and 1993 very closely mirrored the age and sex distribution of the town, and is therefore likely to be representative for the town of Tonbridge. The 6000 population of the study is an epidemiological window on the whole United Kingdom population with migration in and out. There is no evidence from the Office of Population Census and Surveys that there is a tendency for different types of people to move in or out of the town and we believe that the population is reasonably representative of the whole United Kingdom. It is unknown whether ethnicity or social class have any influence on the epidemiology of epilepsy in the United Kingdom. In the United States one study showed a higher prevalence of epilepsy in the black population, ${ }^{13}$ and in Colombia there was a slightly higher rate in patients of a low social class. $^{14}$ 
THE 1983 AND 1993 PREVALENCE SURVEYS

The lifetime prevalence of $20.3 / 1000$ in 1983 and $21 \cdot 0 / 1000$ in 1993 is not significantly different. This is important from a health planning perspective, but as pointed out elsewhere, ${ }^{15}$ similar prevalence results may mask more significant trends in incidence and mortality. The prevalence rates are higher than in other studies in the developed world that have also calculated lifetime prevalence rates with various methodologies, ${ }^{15-19}$ although closer to well conducted door to door surveys, which have reported rates of up to $19 \cdot 5 / 1000 .{ }^{1420}$ When single seizures and unprovoked seizures are excluded the rates are still 14.5/1000 and $14 \cdot 6 / 1000$ in both the 1983 and 1993 survey dates. This reflects the success with which longstanding inactive cases were identified with the general practitioner system. The rates for active epilepsy $(4.3 / 1000$ in 1993) were the same order of magnitude as in other studies. ${ }^{21-25}$

\section{Age and sex distribution}

The age and sex distribution in the two prevalence surveys were similar, both in terms of age of onset and age at time of survey. There is a small decrease in the prevalence of children under 20 years of age in the 1993 (10.2/1000), 95\% CI 5.9-16.3) compared with the 1983 survey $(14.9 / 1000,95 \%$ CI $5 \%$ CI $8 \cdot 3-24 \cdot 6$ ). Lifetime prevalence is reasonably proportional to cumulative incidence in children, ${ }^{15}$ and this fall in the age specific lifetime prevalence rate may be due to a fall in the incidence of epilepsy in children; however the numbers were small and the confidence limits wide. This is discussed when first attendance rates are considered. The female to male preponderance, which was at odds with other prevalence studies, continued in 1993. ${ }^{1524}$ Lifetime prevalence is highest in the middle years of life $(35 \cdot 0 / 1000$ for ages $31-40$ years) whereas the prevalence of active epilepsy is highest in elderly people $(6 \cdot 1 / 1000$ for ages over 60 ). Prevalence surveys that identified patients with active epilepsy have usually reported a peak in children under $20,{ }^{172425}$ whereas lifetime prevalence may be highest in children, ${ }^{19} 20$ or other age groups (30-50 years, ${ }^{20}$ over 70 years ${ }^{15}$ ), and is closely related to the effectiveness of ascertaining cases of inactive epilepsy in each age group. The peak of active epilepsy in elderly people in our study is consistent with data from Rochester and Warsaw, where there was a higher rate in elderly people. ${ }^{1015}$ There is evidence elsewhere that the number of elderly patients has risen over the past 10 years, and the National General Practice Study of Epilepsy (NGPSE) in the United Kingdom found that over $25 \%$ of new onset cases were over $65 .{ }^{26}$ As pointed out, prevalence data do not necessarily mirror incidence data, and although epilepsy is becoming more common in elderly people, it is usually caused by more lethal processes and is associated with a much reduced lifespan, ${ }^{27}$ making it less likely that cases will then feature in prevalence statistics.

\section{Seizure types}

There is little variation between 1983 and 1993. The number of partial seizures is dependent on whether symptoms of partial onset are documented and the level of investigations performed. ${ }^{28}$ This probably explains any interstudy variation. More information is liable to be gained where patients have been classified by syndrome, ${ }^{29}$ or by aetiology. There was a low prevalence of myoclonic seizures, which may serve as a marker for patients who have juvenile myoclonic epilepsy and the other primary generalised epilepsies. This may be partly due to the absence of a patient interview leading to failure to pick up such seizures; however, most young patients were seen by a specialist, and we believe our estimate to be reasonably accurate.

\section{Aetiology}

In agreement with other studies the aetiology is unknown in over $70 \%$ of patients. ${ }^{15}$ This figure depends on the sophistication and degree to which investigations are applied, ${ }^{28}$ and would be expected to decrease with the introduction of CT and MRI. The prevalence population includes a high number of inactive cases who do not warrant any investigation, and it will take many years before the improved investigation of new onset, and the few intractable, cases feed through into the prevalence population. In the NGPSE, which identified patients at the population level in the United Kingdom between 1984 and 1987, the number of unknown aetiologies was considerably less $(61 \%){ }^{26}$ The idiopathic group includes patients with primary generalised epilepsies, but, as discussed, with such a low prevalence of myoclonic and absence seizures the percentage of patients likely to be included in this category is probably small. There is no apparent difference in the type of aetiologies in the 1983 and 1993 surveys, except that the number of traumatic seizures has fallen. This may be related to an overall significant decrease in fatal road accidents in the United Kingdom, probably due to the introduction of new motorcycle and car safety laws. ${ }^{1}$

\section{FIRST ATTENDANCE RATES}

First attendance rates are a measure first used in epilepsy by Zielinski, who calculated the first attendance rates of patients attending a specialist neurological hospital. ${ }^{10}$ These rates were considerably lower than incidence rates estimated from a population based survey, and Zielinski concluded that first attendance rates were a poor guide to incidence. Hospital attendance is a poor way of ascertaining epilepsy, but attendance rates that use general practitioner based populations are, as discussed, a much better method of ascertaining cases of epilepsy in a defined population. First attendance can therefore be used as an estimate of the incidence of epilepsy, but rates calculated retrospectively from a cross sectional population may not be proportional to the incidence. There are four main factors that may affect the relation between the two 
measures ${ }^{10}{ }^{15}$ 30: (1) Patients with epilepsy may move out of the population being surveyed and will therefore be missed in any retrospective method. In our study population however, patients with epilepsy who moved away were then replaced in the surgery list by patients who moved into the area, and so the two variables will cancel each other out unless one predominates. For instance, patients may perceive that a practice offers advantages to patients with epilepsy (there is no evidence for this occurring in the Tonbridge practice). (2) Patients with epilepsy may die and will be missed in retrospective surveys (unless accurate death registers are kept). In a similar population in the United Kingdom, the NGPSE has recently reported on the mortality of patients with epilepsy. ${ }^{31}$ The rate was highest in the first few years, and after five years it was little different from the standard population. Thus in a newly diagnosed cohort of patients with epilepsy in a general practitioner population about $20 \%$ of patients with epilepsy died in the first five years, and thereafter about $1 \%$ died per year. ${ }^{31}$ The deaths mostly occurred in elderly patients and less than $5 \%$ of deaths occurred in patients under 24 years, and all these occurred in the first two years. This means that first attendance rates for patients in the younger age groups are likely to be closer to the true incidence rates and not significantly affected by mortality. (3) Retrospective analysis is prone to miss patients as the data become more incomplete and past occurrences get missed. This is not likely to have a significant affect in our study where all the patient's lifetime history was well documented in the general practitioner's notes, and even single seizures are likely to have been recorded (assuming medical attention was sought). (4) Epilepsy is often difficult to diagnose and in the NGPSE, diagnosis of patients with new onset epilepsy was delayed for more than six months in $20 \%$ of cases. ${ }^{26}$ This is likely to affect the relation between first attendance rates and incidence in the five years before the survey dates. This may suggest that the first attendance rates for the period 1974 to 1983 will be lower when calculated from the 1983 rather than the 1993 survey populations. When this was performed there was no major difference between the two estimations.

Two interesting findings can be made from first attendance rates estimated in our study. Firstly, there has been a decrease in the first attendance rates in children (persons under 20 years) over the years from 1964 to 1993 , with the biggest fall in the past decade. This provides evidence for a corresponding decrease in the number of incident cases. There have only been a few studies that have looked at the influence of time trends on the incidence of epilepsy,,$^{24}$ although the hazards of attempting to determine incidence rates calculated retrospectively from a cross sectional population were not considered in one study. ${ }^{24}$ In Rochester, United States, from 1935 to 1984 there was no significant difference in overall incidence, but this masked strong underlying trends. ${ }^{2}$ The incidence in children declined by $40 \%$ between the earliest and latest time interval, whereas the incidence in the elderly population almost doubled. In an Italian study, the rate varied from 30.5 to $36 \cdot 6 / 100000$ and no significant time trends were found between 1964 and 1978, although the age specific rates were not given. ${ }^{24}$ As the death rate was not taken into account, however, a similar number of new cases in the period 1964-8 compared with $1974-8$ may have been significant, as the further from the survey date so the number of cases ascertained should fall (it is more difficult to ascertain cases when recall of events and records become more sketchy), and the number of cases dying rises. A study recently carried out in northern Sweden found that the incidence of childhood epilepsy (0-15 years) was $89 / 100000$ in the period $1985-7,{ }^{4}$ which compared with $134 / 100000$ when measured by a previous study in $1975 .{ }^{32}$ This represents only two incidence periods, and the differences could have been due to sampling error or different effectiveness of case ascertainment (no confidence limits were calculated).

The second important finding from our study is the high first attendance rates for elderly cases in the 10 years from 1984 to 1993. As discussed, the likelihood of elderly patients with epilepsy dying in the first five years is high, so that the first attendance rates in this age group are likely to be an underestimate of the true incidence, which may be up to $25 \%$ to $50 \%$ higher. This is the first study in which estimates of the incidence of epilepsy in elderly people has exceeded that of children. This has important health service planning implications, with epilepsy services at the primary care and specialist levels needing to be better targeted for this age group.

\section{PROGNOSIS}

Any analyses of the secular trends in the prognosis of epilepsy are hampered by methodological problems that render most studies not comparable-namely, different populations studied with different methodologies. The prognosis of epilepsy before the $1970 \mathrm{~s}$ was held to be poor, with less the $20 \%$ entering remission, ${ }^{33}$ with more recent evidence showing that at the population level over $80 \%$ probably enter long term remission. ${ }^{5}$ This difference is unrelated to the changing fortunes of people with epilepsy, but due to patient selection bias. An improvement in the remission rates has, however, been suggested by Okuma and Kumashiro. ${ }^{34}$ Attention was drawn to studies before the introduction of phenobarbitone (1912) and phenytoin (1938), which indicated that remission rates were as low as $2 \%-30 \%, 3536$ whereas studies in Japan in 1940 and 1952 reported rates of $27 \%$ and $22 \%$, compared with later studies in 1963 and 1969 when the rates increased to $41 \%$ and $45 \% .{ }^{37} 38$ The only data on secular trends of prognosis in a single population comes from the Rochester series. ${ }^{5}$ From 1935 and 1974 no difference in remission rates was found between patients diagnosed in the first 
decade compared with the last. ${ }^{5}$ The authors, however, highlighted the effect of possible confounding factors. For instance, in the first 25 years and in the last 15 years there may have been different mechanisms that were underlying the group classified as "idiopathic" and more successful treatment in the later years may have been masked by the appearance of a more aggressive "idiopathic" form of epilepsy. The other important point is that the incidence of epilepsy in children seems to have fallen, and as this group has the highest remission rates this would lead to a more pessimistic overall view. Despite commenting on this the authors did not then give the age specific remission rates for the earlier compared with the later decades. One more definite indication of improved prognosis in the Rochester series is shown in the relative decline in the total epilepsy population against the increase in the number of patients with single seizures. ${ }^{5}$ The authors speculated that this may be due to earlier and more effective treatment of patients after their first seizure preventing patients from going on to have further seizures. This would also have the effect of decreasing the number of milder cases of epilepsy in the overall epilepsy series and so lower the later overall remission rates.

In our study the overall good prognosis of patients with epilepsy was confirmed with over $80 \%$ entering a two year remission by 10 years. ${ }^{7}$ We did not find any differences between the chances for remission for more recent cases. The proportion achieving two year remission for epilepsy which started after 1 January 1975 was $64 \%$ at four years, compared with $59 \%$ for cases that started before 1 January 1976. For four year remission at 10 years the proportions were $70 \%$ for before 1 January 1974 and $80 \%$ for cases after 1 January 1974 . Only 30 cases for the post1974 group were followed up for more than 10 years, so the level of error is likely to be higher. It is possible that these results may be masking more significant trends and the reduced incidence of epilepsy in children may worsen measurements of the overall prognosis of epilepsy. Further work is needed to document changes in the age specific incidence and prognosis before it is possible to say that recent advances have truly improved the outcome of patients with epilepsy.

The statistical work was carried out by Seema Gupta. We are grateful for the generous support of Action Research (OCC) and the National Society of Epilepsy (SG).

1 Office of Population Census and Surveys. Mortality statistics. London: HMSO, 1991.

2 Hauser WA, Annegers JF, Kurland LT. Incidence of epilepsy and unprovoked seizures in Rochester, epilepsy and unprovoked seizures in Roche

3 Sander JWAS, Cockerell OC, Hart YM, Shorvon SD. Is the incidence of epilepsy falling in the UK? Lancet 1993; the inciden.

4 Sidenvall R, Forsgren L, Blomquist HK, Heijbel J. A community-based prospective incidence study of
epileptic seizures in children. Acta Paediatr 1993;82: epilept
$60-5$.
5 Annegers JF, Hauser WA, Elveback LR. Remission of seizures and relapse in patients with epilepsy. Epilepsia 1979;20:729-37.

6 Okuma T, Kamashiro H. Natural history and prognosis of epilepsy: report of a multi institutional study in Japan. Epilepsia 1981;22:35-53.

7 Goodridge DM, Shorvon SD. Epileptic seizures in a population of 6000 . II: treatment and prognosis. $B M^{f} 1983$ 287:645-7.

8 Commission on Classification and Terminology of the International League Against Epilepsy. Proposal for revised clinical and electroencephalographic classificarevised clinical and electroencephalographic classifica-
tion of epileptic seizures. Epilepsia 1981;22:489-501.

9 Commission on Epidemiology and Prognosis, International League Against Epilepsy. Guidelines for epidemiological studies on epilepsy. Epilepsia 1993;34: 592-6.

10 Zielinski JJ. Epidemiology and medical and social problems of epilepsy in Warsaw. Final report on research program No 19P-58325-F-01. Washington: US:DHEW, Social and rehabilitation service, 1974

1 Schoenberg BS. Calculating confidence intervals for rates and ratios. Neuroepidemiology 1983;2:257-6.

12 Cockerell OC, Sander JWAS, Shorvon SD. Neuroepidemiology in the UK. I Neurol Neurosurg Psychiatry 1993;56:735-8.

13 Haerer AF, Anderson DW, Schoenberg BS. Prevalence and clinical features in a biracial United Stated populaand clinical features in a biracian.

14 Gomez JG, Arciniegas E, Torres J. Prevalence of epilepsy in Bogota, Colombia. Neurology 1978;28:90-4.

15 Hauser WA, Annegers JF, Kurland L. Prevalence of epilepsy in Rochester, Minnesota: 1940-1980. Epilepsia 1991;32:429-45.

16 Tsuboi T. Epidemiology of febrile and afebrile convulsions in children in Japan. Neurology 1984;34:175-81.

17 De Graaf AS. Epidemiological aspects of epilepsy in northern Norway. Epilepsia 1974;15:291-9.

18 Juul-Jensen P, Foldspang A. Natural history of epileptic seizures. Epilepsia 1983;24:297-312.

19 Joensen P. Prevalence, incidence, and classification of epilepsy in the Faroes. Acta Neurol Scand 1986;74: 150-5.

20 Placencia M, Shorvon SD, Paredes V, Bimos C, Sander $\mathrm{JW}$, Suarez $\mathrm{J}$, et al. Epileptic seizures in an Andean region of Ecuador. Incidence and prevalence and region of Ecuador. Incidence and pre

21 Pond D, Bidwell B, Stein L. A survey of 14 general practices. Part 1 medical and demographic data. Psychiatr Neurol Neurochir 1960;63:217-36.

22 Brewis M, Poskanzer CR, Miller H. Neurological disease in an English city. Acta Neurol Scand 1966;42(suppl): $1-89$.

23 Gudmundsson G. Epilepsy in Iceland. A clinical and epidemiological investigation. Acta Neurol Scand 1966; 43(suppl): 1-25.

24 Granieri E, Rosati G, Tola R, Pavoni M, Paolino E, Pinna $\mathrm{L}$, et al. A descriptive study of epilepsy in the district of

25 Sato S. The epidemiological and clinico-statistical study of epilepsy in Nigata City. Clinical Neurology (Tokyo) epilepsy in Nigata

26 Sander JW, Hart YM, Johnson AL, Shorvon SD. National General Practice Study of Epilepsy: newly diagnosed epileptic seizu

27 Cockerell OC, Sander JWAS, Slok EW, Shorvon SD. The mortality of epilepsy: a prospective community based study. Epilepsia 1993;(suppl 2)34:167.

28 Sander JWAS, Shorvon SD. Incidence and prevalence studies in epilepsy and their methodological problems: a review. $\mathcal{f}$ Neurol Neurosurg Psychiatry 1987;50:829-39.

29 Commission on Classification and Terminology of the International League Against Epilepsy. Proposal for revised classification of epilepsies and epileptic syndromes. Epilepsia 1989;30:389-99.

30 Bradford-Hill A. $A$ short textbook of medical statistics. London: Hodder and Stoughton, 1984.

31 Cockerell OC, Johnson AJ, Goodridge DMG, Sander JWAS, Hart YM, Shorvon SD. The mortality of JWAS, Hart YM, Shorvon SD. The mortality of epilepsy: results from the National Gener

32 Heijbel J, Blom S, Bergfors PG. Benign epilepsy of children with centro temporal foci. Epilepsia 1975;16: 657-64.

33 Sander JWAS. Some aspects of the prognosis of the epilepsies; a review. Epilepsia 1993;34:1007-16.

34 Okuma T, Kumashiro $H$. Prognosis of epilepsy: the second interim report of a multi-institutional study in Japan. Folia of Psychiatry and Neurology fapan 1978;32: 421-31.

35 Turner WA. Epilepsy: a study of the idiopathic disease. London: MacMillan, 1907.

36 Habermas S. Uber Die Prognose Der Epilepsie. Allgemeine Zeitschrift für Psychiatrie (Berlin) 1901;58:243-53.

37 Fukishima Y. Prognosis and EEG of epilepsy with special reference to the focal spike abnormality. Clinical EEG (fapan) 1969;11:287-90

38 Wada T. Present state of anti-epileptic drug treatment in Japan. Rinsho-to-Kenkyu (fapan) 1963;40:914. 


\section{MATTERS ARISING}

Prospective evaluation of a prognostic index for intrinsic supratentorial tumours

In their paper published in this fournal Hutton et al conclude that histological grade provided no additional information on survival of patients with intrinsic supratentorial tumours. ${ }^{1}$ This is surprising and contrary to the findings of other workers. ${ }^{2-4}$ One of the problems is that they relied on the Kernohan grading system, which is notoriously subjective. Other groups have pointed out that histological grade using the Daumas-Duport scheme does contribute prognostic information. It would be interesting to know whether if the prognostic index used by the current authors was tested against the Daumas-Duport scheme, histology would still fail to contribute to the prognostic index.

E TESSA HEDLEY-WHYTE Kubik Laboratory for Neuropathology, Massachusetts General Hospital, 14 Fruit Street, Boston, MA 02114-2696, USA

1 Hutton JL, Smith DF, Chadwick DW Prospective evaluation of a prognostic index for intrinsic supratentorial tumours. $\mathcal{F}$ Neurol Neurosurg Psychiatry 1995;59:92-4.

2 Burger PC, Scheithauer BW. Tumours of the central nervous system. Atlas of tumo pathology. Washington, DC: Armed Forces pathology. Washington,
Institute of Pathology, 1994.

3 Daumas-Duport C, Scheithauer BW, O'Fallon I, Kelly P. Grading of astrocytomas, a simple and reproducible method. Cancer 1988;62: 2152-65.

4 Kim TS, Halliday AL, Hedley-Whyte ET, Convery K. Correlates of survival and the Daumas-Duport grading system for astrocytomas. $\mathcal{F}$ Neurosurg 1991;74:27-37.

Hutton et al reply:

That histological grade provided no additional information on survival once a binary variable derived from our index was taken into account is a statement of fact. As Dr Hedley-Whyte is surprised by this fact, we suggest that she uses the index, given in the paper, on data which she has collected. It will be interesting to know whether the Daumas-Duport scheme contributes prognostic information which adds to data that can be obtained by non-invasive methods.

\section{Hemiballism in Parkinson's Disease}

We read with interest the recent interchange between Obeso et $a l$ and Inzelberg and Korczyn in the fournal (1995;58:645-6). Their discussion, and particularly the accompanying diagrams, outline current wisdom with respect to basal ganglia interactions and how changes in the activity of specific structures account for certain clinica manifestations. One critical clinical observation which is not readily explained by the current physiological models of the basal ganglia is the striking amelioration of levodopa-induced dyskinesiae with ventral posterior medial pallidotomy. The benefit obtained from this procedure with respect to primary parkinsonian signs is generally explained on the basis of a reduction in the overactivity of the GABAergic inhibitory input from the pars interna (GPi) to the thalamus (fig 2B, p 646). However, given the extent of the expected pallidal lesioning with this procedure, a pronounced reduction would have been expected in all pallidal outflow resulting in a similar picture to that depicted in fig $2 \mathrm{~F}$ (similar to an extensive lesion in the subthalamic nucleus (STN) causing dyskinesia). Instead, in our experience, mild, shortlived (< one hour) contralateral (and occasional ipsilateral) dyskinesiae occur at the time of lesioning in most patients followed by almost complete elimination of all forms of levodopa-induced dyskinesiae (peak dose dyskinesiae, diphasic dyskinesiae, and off period dystonia) in the contralateral limbs with additional improvements often seen in ipsilateral limbs as well. If the lesion is misplaced or partial (possibly comparable with the effects proposed in fig $2 \mathrm{E}$ with a partial STN lesion), the ameliorative effects of the pallidotomy on levodopa induced dyskinesiae may be only shortlived.

There are other important neuroanatomical problems with the simplified schematic diagrams currently used to explain these clinical states. Figure 2 outlines the "indirect pathway" exclusively. However, as Parent and Hazrati ${ }^{2}$ have recently pointed out, there are major anatomical flaws in this simplification. These authors argue that the projection from the external segment of the globus pallidus (GPe) to the STN does not directly synapse with neurons projecting on to the GPi and substantias nigra (SN) pars reticulata. Instead, they connect with neurons which project back to the GPe forming a closed loop. The GPe then has a direct connection to the GPi which is all but ignored in current anatomical formulations. Another important criticism of current models emphasised by Parent and Hazrati ${ }^{12}$ is the fact that the STN input to the GPi projects predominantly to neurons involved in associative rather than sensorimotor striatal inputs.

It is clear that there is a great deal more to be learned about the interactions of corticobasal ganglia-thalamocortical interactions in health and disease states. Although current models have successfully predicted some clinical findings, they fall well short of satisfactorily explaining many others. Careful electrophysiological, biochemical, and imaging assessments of non-human primates and patients undergoing surgical treatments for Parkinson's disease will hopefully assist in clarifying some of these confounding issues.

ANTHONY E LANG ANDRES LOZANO University of Toronto, The Toronto Hospital, 399 Bathurst St, Toronto, Ontario, Canada MST $2 S 8$

Correspondence to: Dr Lang.

1 Parent A, Hazrati L-N. Functional anatomy of the basal ganglia. I. The cortico-basal ganthe basal ganglia. I. The cortico-basal ganReviews 1995;20:91-127.

2 Parent A, Hazrati L-N. Functional anatomy of the basal ganglia. II. The place of subthalamic nucleus and external pallidum in basa ganglia circuitry. Brain Research Review 1995;20:128-54.
Inzelberg and Korczyn reply:

We are grateful to Lang and Lozano for their comments. They are correct in pointing to some deficiencies in the basal ganglia circuitry which we have suggested in this fournal (1995;58:645-6). Neither have we intended the diagrams to be all inclusive. Intentionally we have omitted the pedunculopontine nucleus, cerebellar contributions, etc, have not differentiated between partial and complete lesions, and have not distinguished between the immediate effects of the lesions and subsequent compensation, to which we refer elsewhere. ${ }^{1}$ We hope, nevertheless, that the simplified diagram suggested by us will be of value to clinicians and scientists interested in movement disorders as it "explains" several neurological conditions.

1 Flash T, Inzelberg R, Korczyn AD. Behav Brain Sci 1995 (submitted).

NOTICE

Announcement from the British Neuropsychiatry Association: 1996 Summer meeting

The 1996 Summer meeting will be held on 14-16 July at Robinson College, Cambridge. It will include topics on neurodevelopment, language, and the presentation of short scientific papers and single case videos by members. The Association's AGM will be held on 16 July.

For further details of these meetings please contact: Sue Garratt, Administrative Assistant, BNPA, 17 Clocktower Mews, London N1 7BB. Telephone/Fax: 0171226 5949.

For details of membership of the BNPA, which is open to medical practitioners in psychiatry, neurology, and related clinical neurosciences, please contact: Dr Fonathan Bird, Secretary BNPA, Burden Neurological Hospital, Stoke Lane, Stapleton, Bristol, BS16 1QT. Telephone: 01179701212 ext 2925/2929 or Sue Garratt at the address given above.

\section{CORRECTION}

Cockerell OC, Eckle I, Goodridge DMG, Sander JWA, Shorron SD. Epilepsy in a population of 6000 reexamined: secular trends in first attendance rates, prevalence, and prognosis. f Neurol Neurosurg Psychiatry 1995;58: 570-60. During production an errồ occurted in table 2 . The third subheading in this table should read Age and sex specific prevalence rates for 1000 persons for 1983 and 1993. Not per 100 as printed. 